\title{
Photovoltaic / thermal systems and its importance in domestic use
}

\author{
Heba A. Mosalam* \\ Energy program, Electomechanics Department, Cairo, Egypt
}

\begin{abstract}
Hybrid photovoltaic thermal solar system becomes one of the potential to play a significant role in the renewable energy sector. The validation of the photovoltaic/ thermal solar system is not valid in Egypt with proven efficiency of both electrical and thermal system. This paper presents a Comparison between Thermal and PVT performance values for the same area with number of 18 units PVT and 14 units' thermal units and other parameters to be discussed during the compression in domestic application, see the parameters and boundaries of selected system, and evaluate the performance of each system.
\end{abstract}

\section{Introduction}

Recent relevant examinations of PVT technologies were conducted by Zhang [1]. Additionally [2] more relevant studies have shown with more technologies. [3] Outlining the various options for the collector's front face (over glazed, non-over glazed, under vacuum), PV emitters (crystalline, thin film, diverse packing factor, semi-transparent), fluid types heat exchanger material and heat exchanger shape, the type of contact, the heat exchanger's fixation, and the backside with or without insulant. The simulation of the photovoltaic and thermal module has illustrated in [4], the researcher used TRNSYS. Also the CSP was used in domestic use in [5]. The aim of that work to compare between types of domestic heating, and see the parameter and boundaries of select and evaluate the performance of each.

\section{Concept of PVT}

Combination PhotoVoltaic - Thermal System (PVT) is a promising solar technology innovation. Various methods are used in these systems to extract heat from solar panels. Separately, the heat extracted is used in thermal systems. The simplest version of the PVT system is seen in Figure 1. PVT was first proposed in. In the same decade, the literature [6] published some theoretical and experimental work on these systems. Water and air were utilized extensively in the beginning to remove heat from PV modules. In the past three decades, technology has progressed. PVT systems with spectrum screens, in addition to collecting heat from PV modules, have recently been explored. PVT systems have been around for almost fifty years. However, the technique has yet to be developed in any

\footnotetext{
* Corresponding author: Heba.mosalam@hu.edu.eg
} 
significant way. It will always be beneficial to discuss the recent happenings in the technology to understand the development and to give the direction for future development. There are some review papers available in the literature describing the different aspects of PVT systems.

The purpose of this paper is to give a wide classification of PVT systems and to describe recent experimental and theoretical work on various PVT systems. A discussion of the usage of liquid-based spectrum filters in PVT applications is also included in the study. A comparison of PVT technologies based on their primary benefits poses a challenge to a researcher.

\section{Water type PVT systems}

Water is utilized as a medium for removing heat from PV modules in these sorts of PVT systems. Theoretical and experimental performance study of water-type PVT systems are primarily found in the literature.

In the majority of situations, the PVT system's hot water is used for household purposes. Figure 1 illustrates the system, which comprises of PV laminates connected to the absorber surface and water tubes to remove heat from the PV module. Pumps are used to circulate the water.

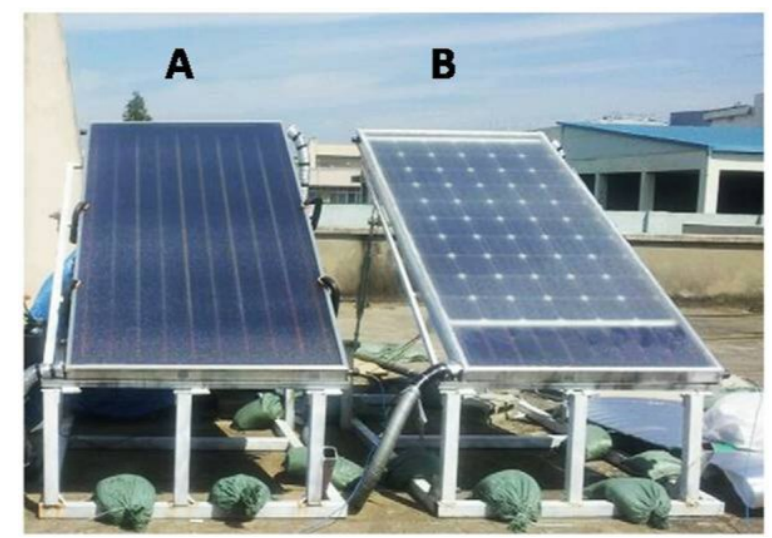

Fig.1. glazed water-PVT system (A: traditional solar Collector B: photovoltaic-thermal Collector).

\section{Air type PVT systems}

Air is utilized as a medium for removing heat from PV modules in these sorts of PVT systems. Theoretical and experimental performance analyses of PVT systems are primarily found in the literature. The work comprises PVT systems with glazing, also without glass, various air channel arrangements. Natural air flow, forced air circulation by fans, inserts in the air channel, air channel depth optimization, and air mass flow rate optimization.

\section{Mathematical model}

For the performance of a covered water type system. As shown in the simulation model, the series connected solar cells were mechanically attached to a roll-bond aluminium absorber, and spectral efficiency, efficiency loss due to temperature, the real angle of incidence of solar radiation on the surface, and the thermal inertia of the system were all 
taken into consideration. The greatest electrical was 10-12 percent and thermal was 20-25 percent for a mass flow rate of $0.055 \mathrm{~kg} / \mathrm{s}$.

\section{Results and discussion}

For the test location 31.25Longitude, 30.05 latitude and 84 elevation. Two simulated test carried out. The first when the preheated units are thermal heaters and the second when the system used PVT units

\subsection{The thermal and photovoltaic thermal units for domestic hot water}

Figure 2 illustrate the system of the preheated water thermal a) illustrate the traditional solar heater and b) illustrate the supply of PV/T. Figure 3 shows the daily maximum temperature ${ }^{\circ} \mathrm{C}$. For the photovoltaic/thermal unit, both annual solar thermal energy and photovoltaic energy production shows in Figure 4. Table 1 shows the components of the system for the location Longitude: $31.25^{\circ}$, Latitude: $30.05^{\circ}$ and $84 \mathrm{~m}$ elevation.

Table 1. overview for the annual values for the domestic hot water unit:

\begin{tabular}{|l|l|l|}
\hline & Solar Heater & PVT \\
\hline $\begin{array}{l}\text { Total fuel or electricity System consumption } \\
\text { [Etot] }\end{array}$ & $7662 \mathrm{kwh}$ & $777 \mathrm{kwh}$ \\
\hline Electricity consumption [Ecs] & $7662 \mathrm{kwh}$ & $8117 \mathrm{kwh}$ \\
\hline Total energy consumption [Quse] & $11692 \mathrm{kwh}$ & $11689 \mathrm{kwh}$ \\
\hline Collector area & $28.3 \mathrm{~m}^{2}$ & $29.5 \mathrm{~m}^{2}$ \\
\hline Solar fraction total & $45.30 \%$ & $41.70 \%$ \\
\hline Total yearly field yield & $6023.2 \mathrm{kwh}$ & $5498.5 \mathrm{kwh}$ \\
Collector field yield respected to gross area & $213 \mathrm{kWh} / \mathrm{m}^{2} / \mathrm{Y}$ ear & $186.3 \mathrm{kWh} / \mathrm{m}^{2} /$ Year \\
Collector field yield respect to aperture area & 235.1 & $193.3 \mathrm{kWh} / \mathrm{m}^{2} / \mathrm{Year}$ \\
Energy savings & $\mathrm{kWh} / \mathrm{m}^{2} / \mathrm{Year}$ & \\
& $6,340.2 \mathrm{kWh}$ & $13128 \mathrm{kWh}$ \\
\hline Max. reduction in CO2 emissions & $3401 \mathrm{~kg}$ & $3105 \mathrm{~kg}$ \\
\hline
\end{tabular}




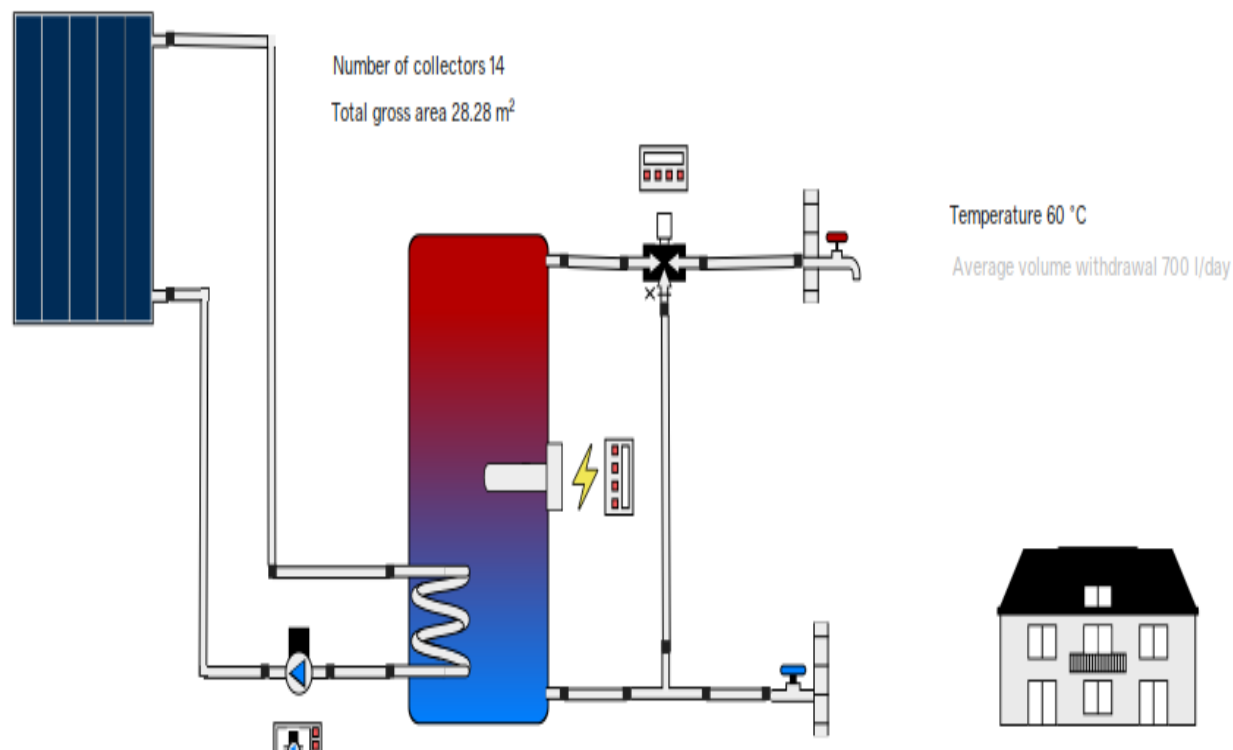

a)

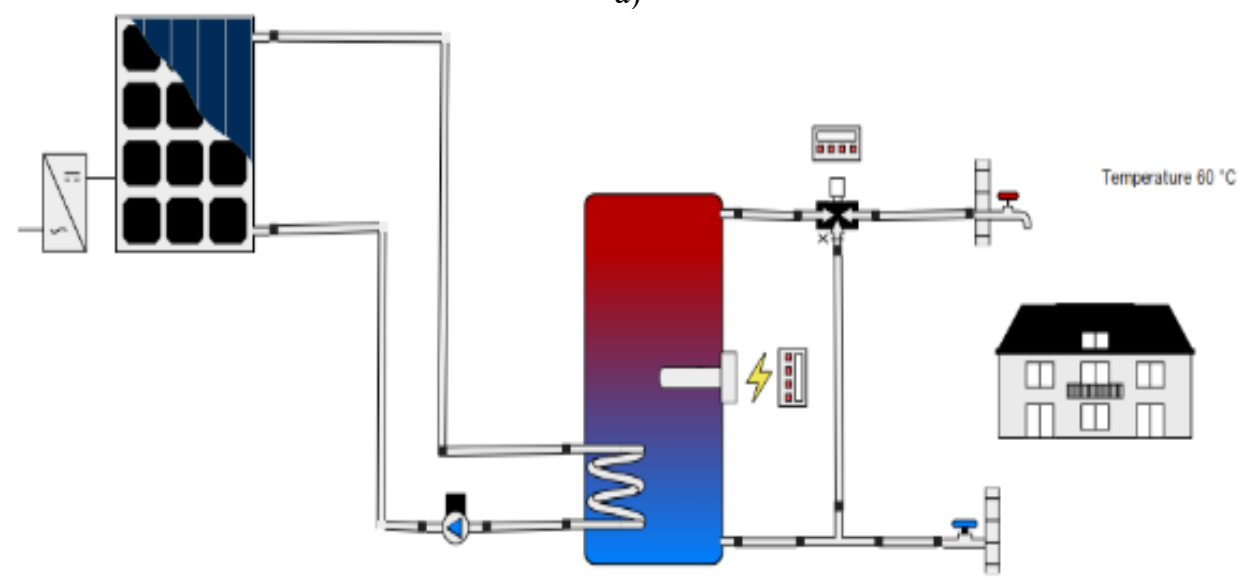

욜

Nurber of modules 18

Total gross area $29.52 \mathrm{~m}^{2}$

PVT collector Wisve $250 \mathrm{M}$ isolated

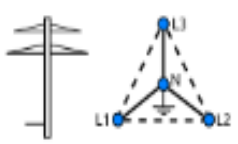

b)

Fig. 2. The solar heater diagram. a) for thermal unit, b) for PVT unit 


\section{Daily maximum temperature $\left[{ }^{\circ} \mathrm{C}\right]$}

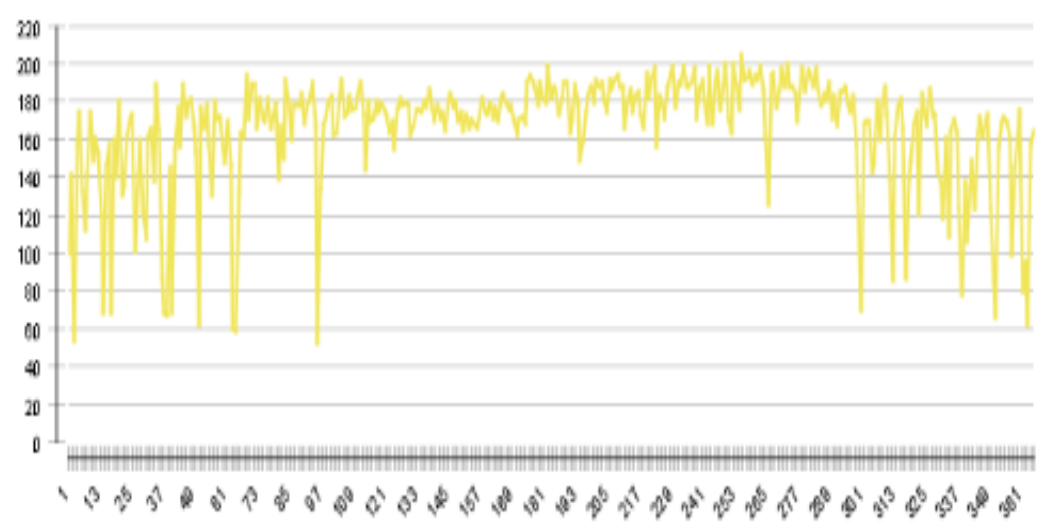

a)

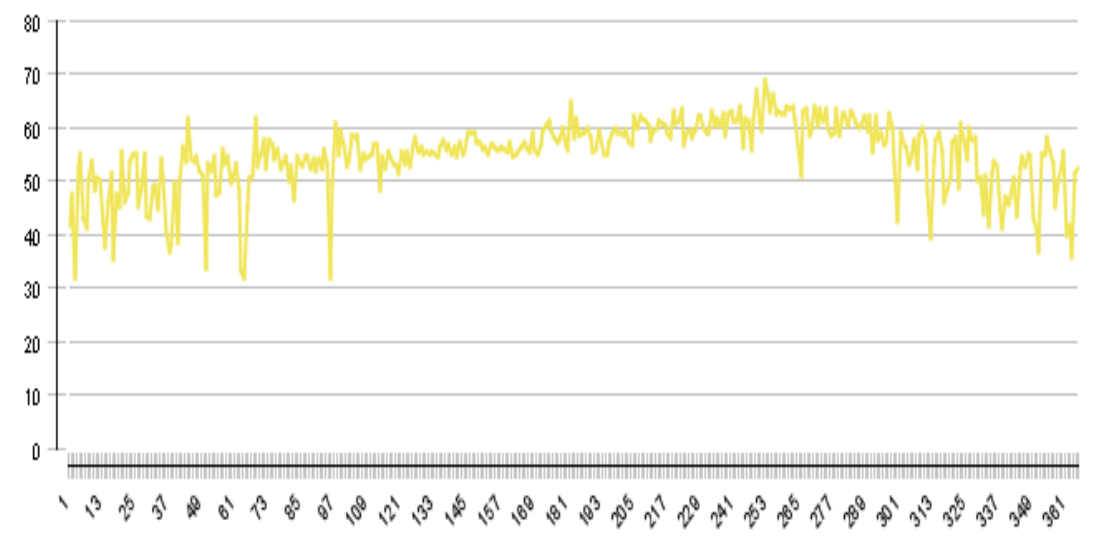

b)

Fig. 3. Daily maximum temperature for a) thermal collector, b) PVT collector 


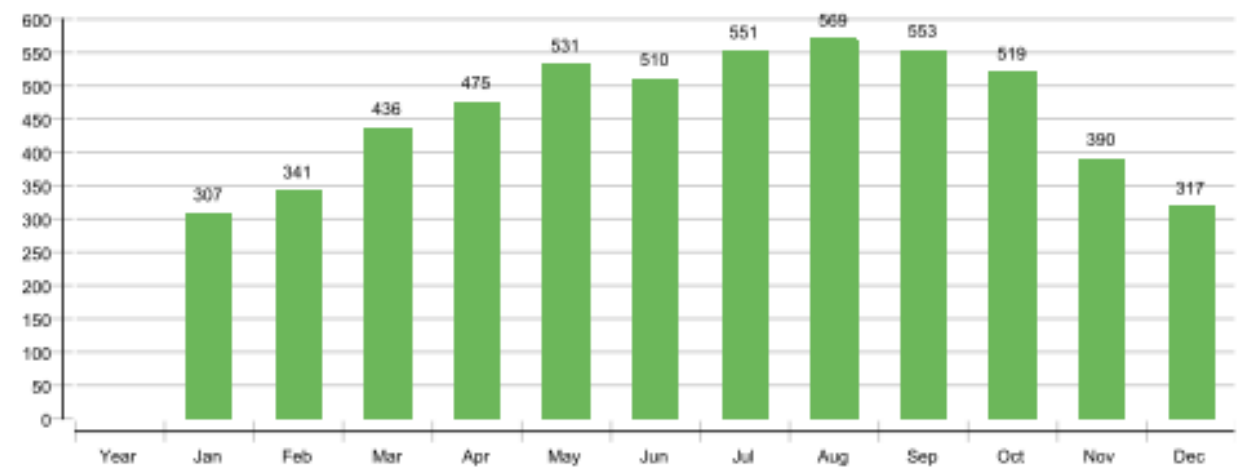

a)

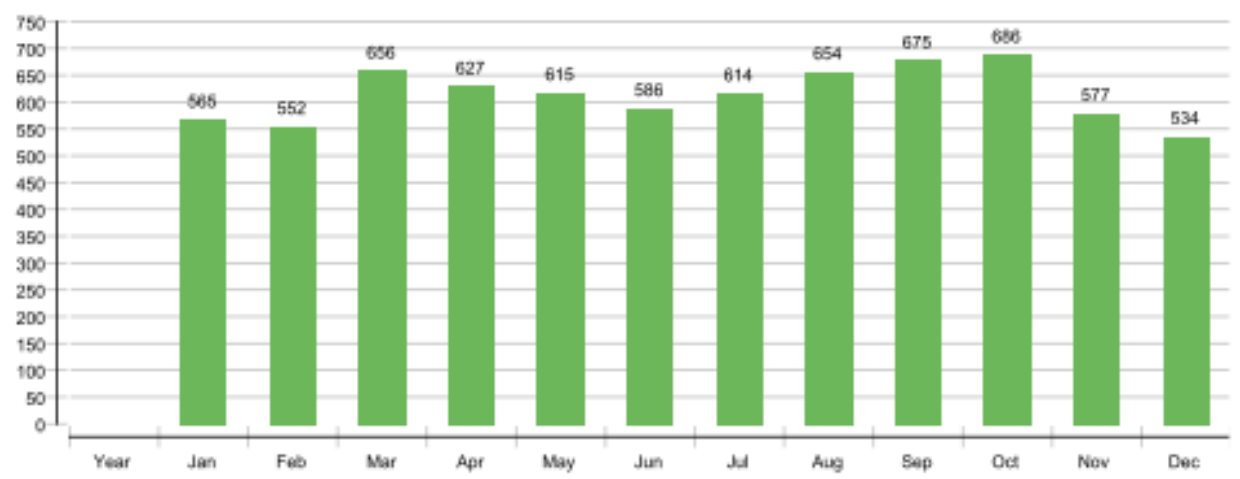

b)

Fig.4. for the PVT, a) the solar thermal energy to the system (Qsol),b) the yield photovoltaic AC (Qinv).

\subsection{Comparison for the two systems performance}

When figure 5, conclude the performance efficiency of photovoltaic/thermal unit.

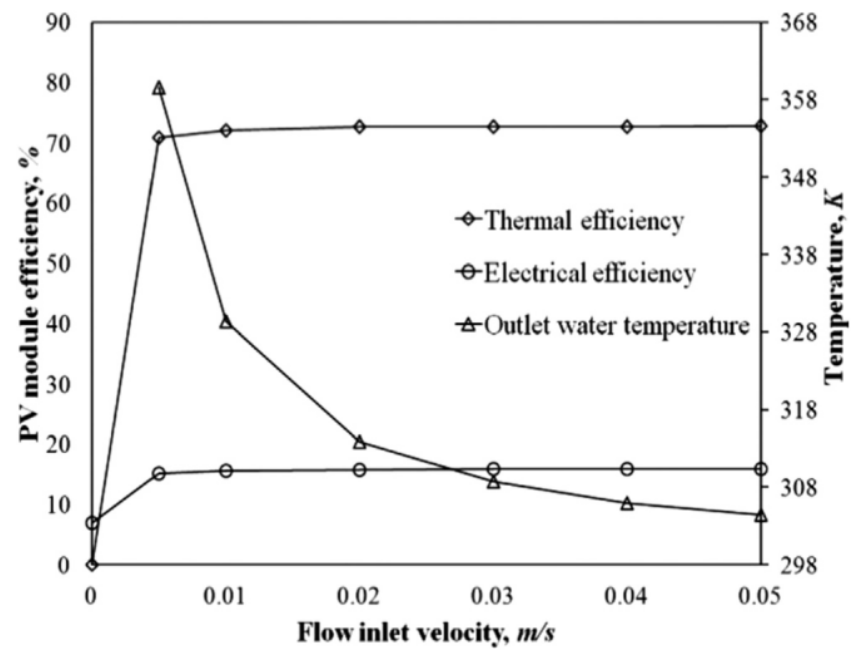

Fig. 5. Performance of PVT system. 
While figure 6 illustrate the energy saved by convert the hot water domestic use to the photovoltaic thermal unit.

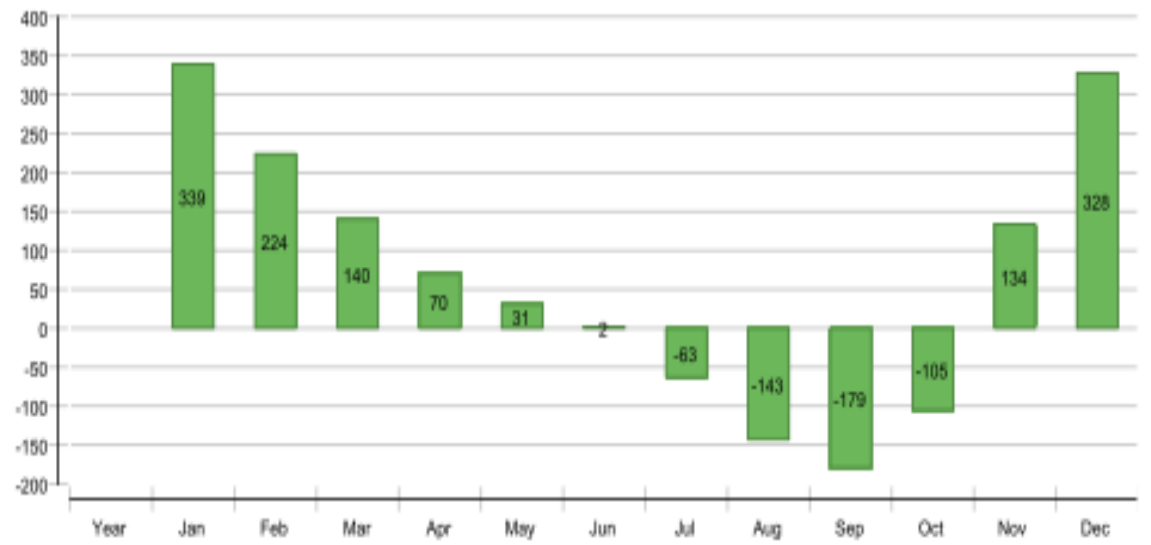

Fig.6. Total electricity consumption of the system of PVT

The results demonstrate the robustness of the non-over glazed PVT as the highest stagnation temperature was measured at $74.2^{\circ} \mathrm{C}$. This temperature level is really safe with regard to the risk of overheating and the impact on PV performance. It shows that the PVT is really suitable for domestic hot water preheating, with a monthly average of the daily maxima of the PVT collector's field output temperature (Tmean) above $45^{\circ} \mathrm{C}$ during 5 months autonomy in the year.

\section{Conclusion}

It was found that the coverage was about $60 \%$ of the hot water needs, and almost autonomy was achieved for 4 summer months. The PVT system provides approximately twice as much energy as a 'PV only' facility with the same module area.For the environmental impact of the PVT, the ratio calculates between the percentages avoided for the carbon dioxide by the photovoltaic to generate electricity to the avoided carbon dioxide by using the solar hot water. Assuming that emissions from PV energy and solar hot water are both zero, the ration will relate to emissions from traditional electricity and hot water systems.

\section{Acknowledgment}

The author thanks the training academy Albirunia for the solar solution for the version simulation of PolySun curves and tables. Also thank Heliopolis University and Mr. Helmy Aboeliesh for his support during the study in Heliopolis University Campus.

\section{References}

1. J. Zhao et al., Energy Convers. Manag., 52(2), 1343 (2011)

2. J. Wu et al., Renew. Sustain. Energy Rev., 75, 839 (2017)

3. D. Das, P. Kalita, and O. Roy, Renewable and Sustainable Energy Reviews, 84, 11 (2018) 
4. M. Lämmle, A. Oliva, M. Hermann, K. Kramer, and W. Kramer, Sol. Energy, 155, 867 (2017)

5. M. Wolf, Energy Convers, 16, 79 (1976)

6. M. Mosalam, Heba; Proceedings of the FRUCT'26 Yaroslavl, Russia, FRUCT Oy, Finland, 583 (2020)

7. L.W. Florschuetz, Proceedings of the 11th IEEE PVSC conference. New York, USA, 318 (1975) 